\title{
Intimate femicide: The role of coercive control ${ }^{1}$
}

\author{
Introduction
}

Governments and non-governmental organizations continue to devote enormous resources to legal responses, service provision, public awareness and prevention initiatives aimed at preventing intimate partner violence and supporting victims, yet it remains a persistent problem affecting approximately three in ten women over their lifetime (World Health Organization, 2013). At its most severe, intimate partner violence results in the death of its victims and sometimes the perpetrator and other family members. In a systematic global review, Stockl, Devries, Rotstein, et al. (2013) estimated that 13.5 percent of all homicides worldwide are committed by intimate partners and that these killings are gendered: partners are responsible for almost 40 percent of homicides involving female victims compared with just 6 percent of homicides against males. The gender division is similar in Australia, where the current study takes place: between 2008 and 2010, 51 percent of female and 9 percent of male homicide victims in that country were killed by intimate partners (Chan \& Payne, 2013).

How to intervene effectively to prevent future violence and an escalation to more serious forms, including homicide, are questions that continue to preoccupy policy makers, service providers and police decades after this issue was firmly established on the public policy agenda. Effective responses require knowledge about how violent relationships are established and maintained as well as the nature of the interactions between violent men and the women they victimize. For example, is intimate femicide (the killing of intimate female partners) a culmination of patterns of violence toward the woman and an escalation in type and frequency?

\footnotetext{
${ }^{1}$ The Australian Homicide Project was supported under Australian Research Council's Discovery Projects funding scheme (Project DP0878364). The authors wish to acknowledge the assistance of the various correctional departments across Australia for their significant support in the conduct of this research. The views expressed in this article are those of the authors and do not represent the policies or views of the correctional departments.
} 
Are there particular characteristics of the man or the relationship that raise the woman's risk of being killed? Or can seemingly ordinary men kill partners in scenarios perceived as "out of the blue" (Dobash, Dobash, \& Cavanagh, 2009) or "crimes of passion" (Dawson, 2005)? This study contributes to these debates and to a growing literature on risk assessment through an examination of situational factors, histories of violence, and background characteristics of a sample of Australian men convicted of killing intimate partners. We first outline the findings of prior research on intimate femicide and highlight the challenges of accurately naming male partner violence that have narrowed policy responses. The method of the Australian Homicide Project is described and the dependent and independent variables selected for this study of intimate femicide are presented in detail. Results of this study highlight the need to remain critical of risk assessments and policies built and defended on the basis of narrow "typifications" that may mistake the danger and fail to provide safety for many abused women.

\section{Prior Research on Intimate Femicide}

The actions of a man who kills his intimate partner can seem inexplicable to many. However, years of analysis by domestic violence death reviews have established that the vast majority of intimate partner killings could be considered predictable and therefore preventable with appropriate interventions that target factors known to be associated with these killings (Dawson, 2017). A history of male violence in the relationship is cited as one of the most important precursors of partner homicide, regardless of the sex of the victim (Campbell, Glass, Sharps, Laughon, \& Bloom, 2007). In a 12-year review of domestic homicides in which the vast majority of victims (82\%) were women, the Domestic Violence Death Review Committee (DVDRC) in the Canadian province of Ontario established 39 associated factors and the most common was a history of violence between the perpetrator and the victim in 72 percent of cases; 
other top correlates were actual or pending separation, obsessive behavior and depression on the part of the perpetrator, escalation of violence, prior threats or attempts at suicide, prior threats to kill the victim, attempts to isolate the victim, perpetrator unemployment, and a sense of fear among victims (Office of the Chief Coroner, 2015).

Risk assessment instruments, which are designed to help avert serious partner violence and femicide and inform professionals and victims about relevant factors associated with increased danger, are growing in number and are considered by many criminal justice, health and social service practitioners to be important tools in the identification and management of these cases (Garcia, Soria, \& Hurwitz, 2007; Messing \& Thaller, 2015). A central component of femicide risk assessments is to identify the seriousness of prior violence as determined by physical injury and escalation in severity and frequency of violent episodes (Campbell et al., 2007). Importantly, although prior physical violence is identified in a majority of femicides, it is absent in a sizable minority. The Ontario DVDRC found a history of violence in three-quarters of intimate partner homicides (Office of the Chief Coroner, 2015) and research in the United States finds that two-thirds to three-quarters of women killed by partners were physically abused before their deaths by the same partner who killed them (Campbell et al., 2007). This leaves a large number without the expected history of violence and without an escalation in frequency and severity of assaults that might lead to intervention by neighbors, family or police. In Ontario, 80 percent of cases contained seven or more precursors which suggests that multiple factors interact to elevate the risk of femicide and escalating violence is not a prerequisite (Office of the Chief Coroner, 2015).

In an extensive analysis of homicide in diverse cultures, Daly and Wilson (1988) identify male partner jealousy, possessiveness and desire to control female partners as important 
precursors for intimate femicide worldwide. This led them to conclude that "sexual proprietariness" is an evolved manifestation of masculinity that interacts with cultural context to produce variations in male violence against women. Violence manifests itself in situations that represent loss of male control over the female partner, such as infidelity (real or imagined) or victim-instigated separation, which trigger extreme jealousy, possessiveness and morbid rage (Wilson \& Daly, 1998; see also Campbell, 1992; Dobash, Dobash, Cavanagh, \& Medina-Ariza, 2007). Femicides are described as "slip-ups" in a power struggle in which men strive to control women and deprive them of their liberty and women struggle for autonomy (Daly \& Wilson, 1988). Among intimate partner homicide cases subject to extensive review by the Domestic Violence Death Review Team in the Australian state of New South Wales, every case involved male partners exerting coercive and controlling behaviors over female victims prior to the homicide (NSW Domestic Violence Death Review Team, 2015). Other correlates of intimate femicide are factors associated with the severity of violence, such as access to and threats with firearms, forced sex, threats to kill and strangulation (Adams, 2007; Campbell et al., 2007; Dobash \& Dobash, 2011; 2015). In terms of demographic and situational factors, de facto relationships, actual or impending separation, the presence of children in the household who are not biologically related to the male partner, and male unemployment and alcohol abuse are also associated with intimate femicide (Campbell et al., 2003; Campbell et al., 2007; Daly, Wiseman, \& Wilson, 1997; Dobash \& Dobash, 2015; Johnson \& Hotton, 2003; Office of the Chief Coroner, 2015).

Research examining intimate partner homicide from the perspective of perpetrators provides important insights into the individual, contextual and situational factors associated with these killings. Dobash and colleagues (2007) compared domestically violent men in behavioral 
change treatment programs and men serving prison sentences for murdering intimate partners in Britain and found that just over half of murderers (59\%) were previously violent toward the woman they killed, calling into question assumptions about a linear progression from increasingly serious assaults to femicide. However, murderers demonstrated other warning signs such as using violence towards previous partners, separation, possessiveness, and elevated risk for lethality at the time of the killing (defined as using serious violence against the victim, such as sexual assault, strangling or choking, or using a weapon). They also found that men who killed intimate partners are more conventional than men who killed other men in the sense that they had fewer problems as children and adults and were less likely to have had persistent criminal behavior (although proportions were high for both groups) or to use physical violence in general despite having prior convictions for assaults against women (Dobash, Dobash, Cavanagh, \& Lewis, 2004). A Finnish study by Kivivuori and Lehti (2012) found that, compared to men who killed other men, men who killed partners were less likely to be unemployed, to be substance abusers, to become violent when intoxicated, and to have a criminal record. Just onethird had convictions for violent offences.

Juodis, Starzomski, Porter and Woodworth (2014) conducted a review of criminal profile and psychological assessment reports on men imprisoned for homicide in Canada and found that those who killed partners were more likely than men who killed other men to be motivated to inflict pain and suffering out of revenge. Male proprietariness and jealousy, the woman leaving the relationship and entering into a new relationship, and disputes over child custody were behind the motivation to take revenge on victims. While 86 percent could have been considered preventable based on known precursors in the Danger Assessment (Campbell, Webster, \& Glass, 2009) — an instrument designed to assess the risk of intimate femicide - the remainder would not 
have been identified as at risk for lethal violence. Within the group of men who murdered intimate partners in the Murder in Britain sample, one-quarter of the killings occurred apparently "out of the blue" without the expected history of persistent criminality (Dobash et al., 2009). The group without prior convictions had more conventional childhoods and adult lives than murderers with prior convictions. However, the two groups were similar in terms of previous violence toward both the victim and women in prior relationships, and factors associated with their orientation toward women and female partners such as possessiveness or jealousy, killing at a time of separation, and lack of remorse or empathy for the victim. Both groups were characterized by prison staff as "having problems with women" (Dobash et al., 2009). The authors" assessment is that "findings do not support the notion of a simple progression from nonlethal to lethal violence and raise some dilemmas for the growing area of risk assessment" (Dobash et al., 2007, p. 329).

This brief review of previous research on intimate femicide cites a history of partner violence and escalation in severity and frequency of assaults as top precursors. However, studies also show that a proportion of femicides do not display this characteristic "battering" that escalates over time and produces evidence of physical injury that signals danger to outsiders and the need to intervene. The context in which a great many femicides take place is one of male dominance and control which is manifested in possessiveness, extreme jealousy, attempts to isolate the women, threats of suicide, and threats to kill that are often triggered by loss of control due to impending separation or real or imagined infidelity. Research finds that, although they are not the majority, killings occurring "out of the blue" are not uncommon and would not have been predicted by risk assessments. We next turn to the challenge of accurately naming male partner violence and abuse which is key to developing effective strategies to prevent it. 


\section{Naming Male Partner Violence and Abuse}

The modern-day women's movement has been the driving force behind what is arguably one of the most important shifts in criminal law and policy in recent years. It was not long ago that men had a right in law and custom to control and chastise their wives without fear of legal sanction or social condemnation (Dobash \& Dobash, 1979). The legal landscape gradually has been transformed to one where violence in the family is no longer considered a private matter and police are instructed to take these crimes seriously by laying criminal charges or applying other sanctions such as protection orders. Pro-charging policies and specialized prosecutorial services and domestic violence courts have proliferated in many jurisdictions alongside behavioral change programs as a sentencing option for perpetrators (Chung, 2015; Hageman-White, Humphreys, Tutty, \& Diemer, 2015). At the core of this broad social movement, men's violence in relationships is portrayed and broadly understood as occurring on a continuum of behaviors that form a pattern of power and control, possessiveness, jealousy and emotional abuse, tools that are readily available for establishing and maintaining male dominance over women and children (Pence \& Paymar, 1986).

As with other social problems, male partner violence became recognized as worthy of public concern and government attention through a lengthy process of claims-making where advocates construct the issue as important and urgent through a presentation of the parameters and the harm to victims. Characterizations are contested by others with interests vested in a different portrayal (or denial) of the problem until a sufficiently broad consensus points to a solution or response about what ought to be done about it (Loseke, 2003). In the struggle to develop the public support needed to persuade governments of the need for emergency shelters for women and arrest of perpetrators, claims-makers required powerful images. The image of a 
"typical" battered woman who is experiencing extreme and ongoing harm was constructed to represent and inspire sympathy for victims and a need for urgent action (Loseke, 2003). This "typification" helped to galvanize attention to the most severe aspects of the problem which inevitably led to narrow solutions targeted at a small, unrepresentative minority of "battered" women (Dunn, 2005). These images help determine the credibility and legitimacy of "real" or "ideal" victims who are worthy of intervention and state assistance and women who fail to live up to expectations of how a terrified battered woman looks and behaves can have their risk of danger misread by police and others and end up killed or prosecuted for the murder of their violent partners whom they killed in self-defence (Randall, 2004; Sheehy, 2014).

Recent attempts to differentiate among types of intimate partner violence stem from concerns that one-size-fits-all responses to diverse forms of violence and abuse cannot be effective for deterring violent men or assisting victims in all circumstances (Holmes, 2015). Johnson's (2006) typology specifies four types: coercive controlling violence (or intimate terrorism), violent resistance, situational couple violence, and common couple violence. The first fits the stereotype of the violent, explosive male intent on systematic patriarchal domination and control over his partner. The victims of these men are the women most commonly served by emergency shelters and hospitals, and they represented the face of the problem of wife battering at the beginning of the battered women's movement. Research in a variety of settings portrays coercive controlling violence as highly gendered, almost exclusively perpetrated by men, and involving a constellation of physical and sexual violence, injury, intimidation and fear (Ansara \& Hindin 2010; Myhill, 2015), yet men in these relationships need not regularly assault female partners to instill terror and ensure cooperation (Stark, 2007). According to Dutton and Goodman (2005, p. 750), “Coercive control doesn’t require a threatened consequence to be actually 
delivered - only creation of the belief that it could be". In other words, the credibility of the threat must be understood in the context of the price of non-compliance (Dutton \& Goodman, 2005).

Government agencies acknowledge the importance of recognizing coercive control in male partner violence. The Australian government, in the National Plan to Reduce Violence Against Women and Their Children, specifies that "...the central element of domestic violence is an ongoing pattern of behavior aimed at controlling a partner through fear, for example by using behavior which is violent and threatening. In most cases, the violent behavior is part of a range of tactics to exercise power and control over women and their children, and can be both criminal and noncriminal" (Council of Australian Governments, n.d., p. 2). Attempts to quantify coercive control and examine its relationship to physical and sexual assaults against intimate partners have used a range of terms and definitions. American forensic social worker, Evan Stark, who popularized the term, defines coercion as the use of force, threats, intimidation, stalking, degradation and shaming to compel a particular response or enforce particular rules; control tactics include isolation, depriving women of resources, exploiting their resources, and regulating their behavior to compel obedience (Stark, 2012). In a national survey on violence against women in the United States, the Centers for Disease Control and Prevention defines coercive control as comprising "behaviors that are intended to monitor and control an intimate partner such as threats, interference with family and friends, and limiting access to money" (Black et al., 2011, p. 10). This is differentiated from psychological aggression, which includes acting dangerous, name calling, insults and humiliation. Forty-one percent of American women have experienced coercive control by intimate partners according to this definition (Black et al., 2011, p. 46). Myhill (2015, p. 362) finds that 30 percent of the partner abuse reported by women in the 
Crime Survey for England and Wales was coercive control, defined as combining "repeatedly belittled you to the extent that you felt worthless" and "frightened you, by threatening to hurt you or someone close to you".

Notwithstanding official definitions that recognize coercive control as central to male partner violence, criminal law and justice systems are mandated to respond to single incidents of assault in a "framework of incidentalism" which fails to incorporate the danger to women in coercively controlling relationships (Kelly \& Westmarland, 2016, p. 115). Police respond just to the specific incident of criminal assault that triggered the call for help and disconnect it from patterns of behavior that control, intimidate and isolate the woman. According to Stark (2007; 2012), current policy responses that rely heavily or exclusively on counting incidents of assault and physical injury as measurements of harm render invisible the power of tactics used to control, isolate, degrade and intimidate women and deprive them of autonomy and freedom and thus fail to protect a great many abused women. Because the criminal law mandates police and prosecutors to respond to discrete incidents, the cumulative effects of low-level violence and non-criminal tactics of control and intimidation that individually may appear trivial are often considered not to merit intervention. As the threats and intimidation and the woman's level of fear escalates and she seeks help, "police and other service providers tend to apply negative stereotypes to these persistent help seekers, seeing them as "repeaters" rather than realizing that their desperation reflects the fact that their abuse is ongoing and that arrest has done little to interrupt it" (Stark, 2012, p. 205). Intense fear often continues following separation when family court-appointed experts fail to recognize the effects of domestic violence and the control these men are able to exert over ex-partners through children (Beck \& Raghavan, 2010; Crossman, 
Hardesty, \& Raffaelli, 2016; Dragiewicz, 2014; Jeffries, 2016; Macdonald, 2016; Tanha, Beck, Figueredo \& Raghavan, 2010).

In summary, in a terrain where the harms of male partner violence are measured by the severity of injury, and where police and criminal courts are mandated to respond to discrete incidents extracted from the broader relational context of ongoing male power and control, the continuation of which can be facilitated by way of contact ordered by family courts, key questions arise for the prevention of intimate femicide. This study adds to the growing body of research examining intimate partner homicide from the perspective of men convicted of killing intimate partners by investigating the role of coercive control, violence in the relationship leading up to the femicide, and other risks identified in prior research. It compares men who describe using violence toward their victims prior to the homicide with those who defy the stereotype and killed their partners but had not previously used non-lethal violence.

\section{Method}

This study examines the histories of a sample of men convicted of killing intimate partners in Australia. Data from the Australian Homicide Project (AHP) were used to compare the backgrounds and characteristics of two groups of men: those who admitted to a history of violence against the victim in the year prior to the femicide and those who reported they had not been violent toward those partners. The complete AHP dataset consists of comprehensive interviews conducted with men and women between 2009 and 2013 at correctional centres and probation and parole offices across Australia. The response rate for this project is difficult to determine with certainty since an unknown number of eligible offenders were not approached for an interview due to concerns for the safety of the researchers. Approximately one-quarter of those who were approached agreed to an interview and, since the sampling frame did not specify 
the relationship between offenders and victims, it is not possible to calculate a response rate for men convicted of killing intimate partners. The full AHP dataset contains data from 302 homicide offenders of whom $86.8 \%$ were male and $13.2 \%$ were female (reference removed for review). Of the total sample, the 68 men who killed female intimate partners are examined in the current study.

\section{Dependent Variable}

The objective of this study was to examine variables that distinguished femicide perpetrators who had been violent toward their victims prior to killing them from those who had not previously used non-lethal violence. Intimate partner violence was measured by the physical and sexual assault questions on the Revised Conflict Tactics Scales (CTS-2) in the 12 months prior to the femicide, combined with single questions about threats to kill a partner and using violence toward a partner in the previous year (one respondent said he used violence toward a partner in the previous year and two said they threatened to kill their partner while denying they used physical or sexual violence on the CTS-2). The sample of men who killed female partners was evenly split between those who described using non-lethal violence against their partners in the previous year (IPV=34) and those who said they had not (non-IPV=34).

\section{Independent Variables}

Variables were selected from the AHP for this analysis on the basis of their relevance in the femicide research literature. ${ }^{i}$ These include personal characteristics of perpetrators, experiences of violence in childhood, use of coercive control toward the victim, and criminal history.

As shown in Table 1, personal characteristics of perpetrators at the time of the homicide included: education (high school education or higher); economic distress in the year prior to the 
homicide (combines being evicted, being unemployed, losing a job, receiving benefits, partner receiving benefits, and being unable to pay bills); relationship separation or threats of separation from female partners; unfaithful partners or perpetrator suspicions of partner infidelity; children living in the household who were unrelated to the perpetrator (stepchildren); perpetrators receiving treatment or assessment by a psychiatrist or doctor for an emotional or mental health problem; suicide attempts by perpetrators; and perpetrators having alcohol or drug abuse problems. Alcohol abuse was assessed by the Alcohol Use Disorders Identification Test (Babor, Higgins-Biddle, Saunders, \& Monteiro, 2001), an instrument containing 10 items referring to alcohol use the year before the femicide with respect to quantity of drinks, inability to stop once started, failure to complete expected tasks, drinking in the morning, guilt or remorse, blackouts, injuries due to drinking, and concerns from relatives, friends or doctors about drinking. This study used the cut point for hazardous and harmful drinking recommended by Babor et al. (2001). Drug abuse was measured by the Drug Abuse Screening Test (DAST-10; National Institute on Drug Abuse, n.d.; Skinner, 1982), a 10-item brief tool designed for clinical screening and treatment and includes questions related to drug use in the year before the homicide such as polydrug use, inability to stop, blackouts and flashbacks, withdrawals symptoms, complaints from family members about drug use, engaging in crime to obtain drugs, and experiencing medical problems due to drug use. Due to small sample counts, the modified DAST scale was categorized according to scoring guidelines and dichotomized into no or low level drug problem and moderate, substantial or severe drug problem (see https://www.drugabuse.gov/sites/default/files/files/DAST-10.pdf for scoring guidelines).

Experiences of violence in childhood were measured by two sets of questions: one set asked about physical and sexual abuse and neglect on a 5 point scale, including how often they 
had been beaten so badly that it left marks, were ashamed to be seen by others or needed to see a doctor, were sexually abused by parents or someone else, or parents neglected their physical or emotional needs. Respondents were considered to have been abused if they replied that they experienced physical or sexual abuse sometimes, often or very often. Neglect of physical and emotional needs was excluded because it is, to a great extent, determined by availability of resources. Those who said they never or hardly ever had these experiences were coded as not having been abused. A separate question asked respondents how often their father beat their mother using the same 5 point scale and cut-off point where sometimes, often or very often were scored as having witnessed paternal violence.

The use of coercive and controlling tactics toward deceased partners was measured by four items. First, the Relational Entitlement and Proprietariness Scale (REPS) developed by Hannawa, Spitzberg, Wiering and Teranishi (2006) contains 28 items on a 7 point Likert scale and, due to a small sample, rather than calculating means, each item was dichotomized so that if the respondent slightly agreed, agreed or strongly agreed with at least one item he was considered to exhibit controlling behavior. Examples of the items contained on the REPS are: I have the right to contact my partner's friends to see how she acts without me around; I look through my partner's drawer, handbag or pockets; and, if my partner leaves me I'll make sure she regrets it. Second, psychological abuse was defined as ever using the psychological aggression items on the CTS-2 which includes such behaviors as insulting or swearing at his partner, calling her names such as fat or ugly, shouting or yelling, destroying property, and threatening to hit or throw something at her. The third type of coercive control is sexual jealousy measured by a modified version of a jealousy-provoking scale developed by Salovey and Rodin (1988) in which eight of the 10 original items designed to assess jealous in the romance domain 
were presented to respondents. While Salovey and Rodin (1988) asked respondents to indicate on a 7-point Likert scale the level of jealousy they experienced in each situation, the approach taken for this project was to ask respondents "How upset would this make you feel?" Response categories were not at all, a little, somewhat and very upset. Items included situations such as the partner having lunch with an attractive man, dancing closely with another man, visiting a person she used to go out with, or talking about an old lover. Respondents who would be "very upset" to any two of the eight items were considered to be high on sexual jealousy. A decision was made to establish a cut-off of two situations since being upset about one item - his partner having an affair - is a low threshold and two-thirds of femicide perpetrators said they would be very upset about this. If this were the only item that would cause the person to be very upset, he would not be classified as sexually jealous. The fourth indicator of coercive control is stalking female partners within the year prior to the femicide.

Extensive information concerning criminal history was gathered in the AHP. Participants reported on a wide range of violent, property and drug crimes committed in their youth and adulthood (whether or not they were arrested or convicted) as well as the age at which they first became involved in each type of crime. In this analysis, violent crime is defined as assault, sexual assault and robbery, property crime as theft, property damage, possession of stolen goods and deception offences, and drug crime as selling marijuana, hash or hard drugs such as heroin, cocaine or LSD. Early onset of offending is as having committed any type of crime before the age of 13 . The survey also enquired about being arrested as a juvenile which, at the time of data collection, was 17 years of age or younger in all but one state in Australia. Violence toward any previous partner was measured by ever having used physical violence (examples provided to respondents were punching, hitting and slapping), sexual violence or abuse, caused injury 
requiring medical treatment, or had a previous partner take out a domestic violence protection order. Using violence toward people other than intimate partners or other family members referred to the year prior to the femicide and included four items: hitting, threatening to hit, using physical violence or threats to make someone have sex, and attacking someone with the idea of seriously hurting or killing them. Having had problems with the law due to domestic violence also referred to the previous year and encompassed having a legal order preventing the person from approaching their partner and having the police come to their home because of domestic violence. Having had other problems with the law in the year prior to the homicide event included being arrested, spending time in prison or on probation, parole, or any other type of correctional order, or being in trouble with the law in any other way.

\section{Results}

Femicide perpetrators in the AHP demonstrated many of the correlates identified in previous research and domestic violence death reviews. Among the total sub-sample of 68 men convicted of killing intimate female partners, just one-third had a high school education and over half were in economic distress in the year prior to the homicide event (Table 1). About half were separated or their partner had threatened to leave them and about one-third knew or suspected that their partner was cheating on them. One-quarter lived in households with stepchildren. Sixteen percent had received treatment or assessment by a psychiatrist or doctor for an emotional or mental health problem; however, this question excludes those with undiagnosed and untreated mental health problems and therefore may undercount the extent of mental health problems among this population. Similar percentages had attempted suicide and met the criteria for hazardous or harmful drinking while three in ten had moderate, substantial or severe drug problems. A minority of men in this is a sample was raised in homes with violence: 40 percent 
were victims of childhood physical or sexual abuse and one-fifth had fathers who were violent toward their mothers.

These men also exhibited high levels of coercive controlling behaviors leading up to the femicide. Almost half were controlling and proprietary, two-thirds were psychologically abusive, one-quarter exhibited sexual jealousy, and one-fifth stalked their victims prior to killing them. Criminal histories were extensive. Almost two-thirds of these men had histories of violent crime, a similar proportion had been involved in property crime, and one-quarter in dealing drugs. One in three began offending before they reached the age of 13 and the same proportion were arrested as a juvenile. In the year prior to the femicide, half had been violent toward the women they killed, half had used violence toward previous partners, and one-fifth were violent toward others outside the home. This high level of violence is not reflected in their encounters with the criminal justice system: just 26 percent report problems with the law related to domestic violence and 21 percent had other problems with the law during the previous year.

With fully half of the men in this study claiming not to have used violence in their intimate relationship prior to killing the woman an important question arises: do these men who did not have the violent background expected of men who kill their intimate partners demonstrate other indicators of dangerousness or were their actions inexplicable events that came "out of the blue"? Table 1 presents a comparison of two groups of femicide perpetrators: those with a history of intimate partner violence toward the victim (IPV, N=34) and those without a history of violence (non-IPV, N=34). Chi-square tests with a 10 percent threshold were used to test for significant differences between the two groups to reduce the likelihood of Type II errors resulting from a small sample. Differences were noted on 12 dimensions. Femicide perpetrators without a history of IPV were more likely than domestically-violent perpetrators to 
have completed high school and were less likely to be separated or threatened with separation. They were less likely to have problems with alcohol and less likely to have grown up witnessing or experiencing violence by parents. They were lower on two indicators of coercive control: psychological abuse and stalking. Men without a history of IPV also had lower levels of prior criminality: they were less likely to have been involved in property crime or drug dealing, less likely to be violent toward others outside the home, and less likely to have problems with the law, both related and unrelated to domestic violence.

Although these two groups present some important differences with respect to risk for femicide, the similarities stand out. Men who killed within a context of intimate partner violence and those without a history of IPV were equally likely to be economically distressed. One-third of both groups knew or suspected their partner was unfaithful to them and an equal percentage had stepchildren. The two groups showed no significant difference with respect to mental health assessment or treatment, attempted suicide or drug abuse. They were not significantly different on controlling and proprietary behaviors or sexual jealousy. Although IPV men were more likely to be violent toward others outside the home in the previous year, there were no statistically significant differences between the two groups with respect to having been involved in violent crime over their lifetime, using violence toward a previous partner, early onset of offending, or arrest as a juvenile.

To account for the overlap in many of these factors, and the statistical probability of chance findings when calculating numerous associations, conceptually similar factors related to coercive controlling behaviors, mental health and substance abuse, and criminal history were grouped and comparisons made on these groupings between men with a history of IPV and nonrelationally violent men. Results in Table 2 show that men with a history of IPV were 
significantly more likely than men who were not violent toward their partners prior to the femicide to use varieties of coercive control, although 62 percent of non-IPV men also reported using these behaviors. No difference were found between these two groups on combined mental health and substance abuse, or on criminal histories, which included violent criminality, early onset of offending, using violence toward a previous partner, and having other problems with the law. The mean count of these combined risks was not significantly different for the two groups.

\section{Discussion}

The objective of this research study was to investigate the extent to which intimate femicide is preceded by physical violence toward the victim and to investigate other warning signs, including but not limited to forms of coercive control, which could help inform interventions. In this analysis, we explored the backgrounds of men convicted of killing female intimate partners and compared men with and without the expected history of violence toward their partner. The AHP sample of 68 femicide perpetrators were evenly split between those who said they had used violence and those who said they had not. Although the small sample limits conclusions that can be drawn, some important findings emerge.

First, similar to the Murder in Britain study, femicide perpetrators without a history of violence toward the women they killed were more conventional than relationally violent men in the sense that they had higher education and were more likely to have intact relationships, no problematic alcohol use, and non-violent childhoods (Dobash et al., 2009). They were less likely to be coercively controlling toward female partners in some ways but not others: they had lower levels of psychological abuse and stalking, but were similar to IPV men in levels of controlling and proprietary behavior and sexual jealousy which lends support to Wilson and Daly's (1998) 
theory that sexually proprietary men may use lethal violence in situations signifying loss of control over female partners where non-violent methods were once sufficient.

There were no statistically significant differences between IPV and non-IPV men in the percentage who were economically distressed or the percentage who had stepchildren or suspected their partner of being unfaithful, which have been cited as factors contributing to sexual proprietariness and intimate femicide (Wilson \& Daly, 1998). Non-IPV men were similar to IPV men on mental health problems and drug abuse. Men who reported no violence toward the women they killed had fewer interactions with police in the year prior to the femicide. These men also had lower histories of property and drug crime over their lifetime; however, histories of violent crime were no different than for IPV men, nor were early onset of offending or violence toward previous partners.

When these factors are combined, there is no significant difference between the two groups in the level of danger to female partners on criminal history or substance abuse and mental health problems. Although combined coercive controlling behaviors were higher for men with a history of IPV, 62 percent of non-IPV men reported using varieties of coercive control against the women they killed, and one in five had a legal order preventing them from approaching their partner or had the police come to their home because of domestic violence in the year prior to killing their partners. In the absence of outright assaults, these women were sufficiently fearful or threatened to request police protection which was issued in the form of a protection order or other non-criminal intervention. These interventions were ineffective in protecting them. Half of the non-IPV men had been violent toward previous partners which adds to the credibility of the threats and the danger these men represented. 
The relatively high levels of prior violence and other criminal offending for the men in this sample raise questions about heterogeneity of offending and whether there are distinct subgroups of femicide offenders. The Murder in Britain study finds that femicide perpetrators as a group are more specialized in their criminality than other homicide perpetrators (Dobash et al., 2004). Among the intimate femicide perpetrators in this study, the non-IPV men can be described as more conventional than those with a history of violence toward the women they killed, although the many similarities between the two sub-groups point to generalities in precursors to intimate femicide that extend beyond a past history of violence toward the female victim. The two groups had comparable levels of mental health and substance use problems and criminality, and although coercive control was higher for the IPV men, almost two-thirds of nonIPV men also described using these behaviors. The femicide perpetrators were generally violent and did not limit their violence to female partners. When all relationally violent men are counted (those who had been violent toward a previous partner combined with those who were violent against the deceased partner) the total is 66 percent. The same percentage admitted to violent offending at some point in their lives or using violence toward others apart from intimate partners. The crossover in targets for violence is apparent: a majority of men (71 percent) who were relationally violent had also used violence toward others and half of the sample had been violent toward both intimate partners and others, demonstrating a generality in the use of violence for a substantial proportion. Qualitative interviews and quantitative analyses of larger samples are needed to map types of intimate femicide and help specify the role of coercive control in the femicide incident, and how it clusters with others factors to raise the danger to female partners over time. 


\section{Limitations}

The sample of 302 homicide offenders in this dataset and the 68 men who were convicted of killing their female partners is one of a few studies to interview men directly about the contexts in which these homicides took place. Firsthand accounts from perpetrators offer a unique perspective into motivations and precursors for intimate femicide. In addition, convicted homicide offenders can be considered one of the most complete and representative samples of perpetrators because, with the exception of homicides that end in suicide of the perpetrator, the vast majority are detected and investigated by police and governments dedicate significant resources to investigations and prosecutions.

However, there are limitations inherent in interviewing convicted offenders about their violence. The sample of femicide perpetrators is small and consists of those who were available at the time designated by the prison administration and the availability of the interviewer, and who were willing to talk about their crimes. The relatively small sample precludes possibilities for multivariate analyses, although results point to fruitful areas for future research with men who kill intimate partners, given some similarities between our two groups but also evidence of diversity among them with respect to histories of violence. Community-based control groups of relationally violent men and non-violent men would help further differentiate levels of violence and abuse by types of coercive control and other factors, and how coercive control is related to the decision to use violence against or to kill female partners.

With respect to the dependent variable, the decision was made to focus on male offenders' reports of violence they inflicted on their female partners in the year prior to the homicide in order to enhance reliability of recall. Results may have differed had we broadened the time at risk of using violence by including the entire relationship. Elements of coercive 
control as they were measured in this study lack specificity, particularly sexual jealousy which was measured via a jealousy-provoking scale in which respondents indicated they would be very upset in two of the following situations: their partner having lunch with an attractive man, dancing closely with another man, visiting a person she used to go out with, talking about an old lover, or having an affair. These items arguably have a low threshold and fail to offer possibilities for capturing unfounded jealousy or imagined infidelities and unjustified fears of separation which are more closely aligned with Wilson and Daly's theory of sexual proprietariness. Moreover, items specifically measuring isolation, deprivation of resources and commanding obedience would have allowed more accurate testing of Stark's (2007) conceptualization of coercive control.

An additional potential threat to the reliability of the dependent variable entails concerns about the tendency of violent men to deny, minimize and justify their actions and their reluctance to discuss motivations (Dobash \& Dobash, 2004, 2011; Hearn, 1998; Kelly \& Westmarland, 2016). The "framework of incidentalism" may have allowed these men to represent acts of violence against their female partners as "one-offs" and not "real violence" (Kelly and Westmarland, 2016). Yet, ambiguously, while violent men downplay the effects on their partners, claim not to remember and shift responsibility and blame, research also finds that they recount their violence in purposeful detail, committed with the intention of punishing or intimidating their partners or showing them who is boss (Cavanagh, Dobash, Dobash, \& Lewis, 2001). Population surveys that interview samples of men about their violence and corroborate their accounts with female partners suggest that underreporting on violent behavior may, in fact, be less severe than previously thought (Barker, Contreras, Heilman, Singh, Verma, \& Nascimento, 2011 ; Fulu, Warner, Meidema, Jewkes, Roselli, \& Lang, 2013). Further 
corroboration is needed to determine the extent of denial of previous IPV and other criminal behavior specifically among convicted homicide offenders.

\section{Conclusion}

Coercive control provides the backdrop against which much male partner violence takes place, but this study shows that extreme violence - femicide - can take place in relational contexts of male control and intimidation where expected warning signs of escalating assaults and injury are absent. Half of the femicide perpetrators in this study of convicted offenders described no physical or sexual violence toward their female partners in the year prior to the killing and were more conventional than relationally violent men. Although coercive control was used less frequently by non-IPV men, almost two-thirds used these tactics in varying forms.

Male control over female partners is made possible, broadly practised and socially acceptable in contexts where physical violence may be unacceptable, and on its own may not register as warning flags that signal danger of lethal violence. The typification of the battered woman that was important for establishing the urgency of legal interventions into male partner violence has produced narrow images of legitimate and worthy victims that exclude many women whose lived experiences fail to conform. Incident-based justice responses that assess severity of abuse via physical injury and extract seemingly minor assaults and threats from ongoing coercive control may overlook possible points of intervention that could help prevent femicide. Without an understanding of the entrapment that can result from coercive control in the absence of physical assaults, "why doesn't she just leave" remains a puzzle for many, inside and outside the criminal justice system (Stark, 2007).

The results of this study show that it is important to distinguish between violence as defined by criminal law and abusive behaviors that degrade and instill fear and that, although 
coercion and control often form part of a constellation of violence and abuse, behaviors that effectively entrap and isolate female partners while obviating the need for ongoing and escalating assaults may pose an even greater danger. This has implications for risk assessment. Relatively rare events like femicide are very difficult to predict but the findings of this study suggest that risk assessments that prioritize assaults that intensify in frequency and severity, in some situations, may overlook the danger inherent in efforts to control, isolate and terrorize women when assaults and injury are absent or considered by law to be minor. Further research is needed to identify the constellation of factors that interact with coercive control to elevate the risk of femicide when escalating assaults and injury are absent.

The government of the United Kingdom has recently recognized controlling and coercive behavior in intimate or familial relationships as a criminal offence, defined as "a purposeful pattern of behavior which takes place over time in order for one individual to exert power, control or coercion over another" (Home Office, 2015, p. 3). It is too soon to say what effect this legal reform will have on the "framework of incidentalism" (Kelly \& Westmarland, 2016) or awareness of the power of coercive control to entrap and endanger women. As this study shows, justice for abused women demands that we remain critical of narrow framings of intimate partner violence and the influence these framings have over criminal justice law and policy that denies many abused women the protection of the law.

\section{References}

Adams, D. (2007). Why do they kill: Men who murder their intimate partners. Nashville, TN: Vanderbilt University Press. 
Ansara, D. \& Hindin, M. 2010. Exploring gender differences the patterns of intimate partner violence in Canada: A latent class approach, Journal of Epidemiology and Community Health, 64, 849-854.

Babor, T. F., Higgins-Biddle, J. C., Saunders, J. B., \& Monteiro, M. G. (2001). AUDIT The Alcohol Use Disorder Identification Test: Guidelines for use in primary care (2nd ed.). Geneva: World Health Organization.

Barker, G., Contreras, J.M., Heilman, B., Singh, A.K., Verma, R.K., \& Nascimento, M. (2011). Evolving men: Initial results from the International Men and Gender Equality Survey (IMAGES), Washington D.C.: International Center for Research on Women, and Rio de Janeiro, Brazil: Instituto Promundo.

Beck, C.J.A., \& Raghavan, C. (2010). Intimate partner violence screening in custody mediation: The importance of assessing coercive control, Family Court Review, 48(3), 555-565.

Black, M.C., Basile, K.C., Breiding, M.J., Smith, S.G., Walters, M.L., Merrick, M.T., Chen, J., \& Stevens, M.R. (2011). The National Intimate Partner and Sexual Violence Survey (NISVS): 2010 Summary report. Atlanta, GA: National Center for Injury Prevention and Control, Centers for Disease Control and Prevention.

Campbell, J.C. (1992). "If I can’t have you, no one can”: Power and control in homicide of female partners. In J. Radford \& D.E.H. Russell (Eds.), Femicide: The politics of woman killing (pp. 99-113). New York, NY: Twayne.

Campbell, J.C., Glass, N., Sharps, P.W., Laughon, K., \& Bloom, T. (2007). Intimate partner homicide: Review and implications of research and policy. Trauma, Violence, \& Abuse, $8(3), 246-269$. 
Campbell, J.C., Webster, D.W., \& Glass, N. (2009) The Danger Assessment: Validation of a lethality risk assessment instrument for intimate partner femicide. Journal of Interpersonal Violence, 24(4): 653-674.

Campbell, J.C., Webster, D., Koziol-McLain, J., Block, C., Campbell, D., Curry, M.A., Laughon, K. (2003). Risk factors for femicide in abusive relationships: Results from a multisite case control study. American Journal of Public Health, 93(7), 1089-1097.

Cavanagh, K., Dobash, R. E., Dobash, R. P., \& Lewis, R. (2001). “Remedial work”: Men’s strategic responses to their violence against intimate partners. Sociology, 35(3), 695-714.

Chan, A., \& Payne, J. (2013). Homicide in Australia: 2008-09 to 2009-10 National Homicide Monitoring Program annual report. Canberra: Australian Institute of Criminology.

Chung, D. (2015) Behavior change programs for intimate partner violence abusers: A means to promote the safety of women and children? In H. Johnson, B. Fisher, \& V. Jaquier (Eds.), Critical issues on violence against women: International perspectives and promising strategies (pp. 171-182). London: Routledge.

Council of Australian Governments. (n.d.). National plan to reduce violence against women and their children, 2010-2022. Retreived from https://www.dss.gov.au/sites/default/files/documents/08_2014/national_plan1.pdf

Crossman, K.A., Hardesty, J.L., \& Raffaelli, M. (2016). "He could scare me without laying a hand on me": Mothers' experiences of nonviolent coercive control during marriage and after separation. Violence Against Women, 22(4), 454-473.

Daly, M., \& Wilson, M. (1988). Homicide. New York: Aldine De Gruyter.

Daly, M., Wiseman, K.A., \& Wilson, M. (1997). Women with children sired by previous partners incur excess risk of uxoricide. Homicide Studies, 1(1), 61-71. 
Dawson, M. (2005). Intimate femicide followed by suicide: Examining the role of premeditation. Suicide and Life-Threatening Behavior, 35(1), 76-90.

Dawson, M. (Ed.). (2017). Domestic homicides and death reviews: An international perspective. Basingstoke, UK: Palgrave Macmillan.

Dobash, R.E., \& Dobash, R.P. (1979). Violence against wives: A case against the patriarchy. New York: Free Press.

Dobash, R. E., \& Dobash, R. P. (2011). What were they thinking? Men who murder an intimate partner. Violence Against Women, 17(1), 111-134.

Dobash, R.E., \& Dobash, R.P. (2015). When men murder women New York: Oxford University Press.

Dobash. R.P., \& Dobash. R.E. (2004). Women's violence to men in intimate relationships: Working on a puzzle. British Journal of Criminology, 44(93), 324-349.

Dobash, R.E., Dobash, R.P., \& Cavanagh, K. (2009). "Out of the blue": Men who murder an intimate partner. Feminist Criminology, 4(3), 194-225.

Dobash, R. E., Dobash, R. P., Cavanagh, K., \& Lewis, R. (2004). Not an ordinary killer—just an ordinary guy: When men murder an intimate woman partner. Violence against Women, 10(6), 577-605.

Dobash, R. E., Dobash, R. P., Cavanagh, K., \& Medina-Ariza, J. (2007). Lethal and nonlethal violence against an intimate female partner. Violence against Women, 13(4), 329-353.

Dragiewicz, M. (2014). Domestic violence and family law: Criminological concerns. International Journal for Crime, Justice and Social Democracy, 3, 121-134.

Dunn, J.L. (2005). 'Victims' and 'survivors': Emerging vocabularies of motive for 'battered women who stay'. Sociological Inquiry, 75(1), 1-30. 
Fulu, I., Warner, X., Meidema, S., Jewkes, R., Roselli, T., \& Lang, J. (2013). Why do some men use violence against women and how can we prevent it? Quantitative findings from the UN Multi-county Study on Men and Violence in Asia and the Pacific, Bangkok: UNDP, UNFPA, UN Women and UNV.

Garcia, L., Soria, C., \& Hurwitz, E.L. (2007). Homicides and intimate partner violence: A literature review. Trauma, Violence, \& Abuse, 8(4), 370-383.

Hageman-White, C., Humphreys, C., Tutty, L., \& Diemer, K. (2015). Overview of current policies on arrest, prosecution, and protection by the police and the justice system as responses to domestic violence. In H. Johnson, B. Fisher, \& V. Jaquier (Eds.), Critical issues on violence against women: International perspectives and promising strategies (pp. 47-65). London: Routledge.

Hannawa, A.F., Spitzberg, B.H., Wiering, L., \& Teranishi, C. (2006). “If I can’t have you, no one can": Development of a Relational Entitlement and Proprietariness Scale (REPS). Violence and Victims, 21(5), 539-560.

Hearn, J. (1998). The violences of men. London: Sage.

Home Office. (2015) Controlling or coercive behavior in an intimate or family relationship: Statutory guidance framework. London: Home Office.

Holmes, M. (2015). What do we mean by domestic violence? Mandatory prosecution and the impact on partner assault response programs. In H. Johnson, B. Fisher, \& V. Jaquier (Eds.), Critical issues on violence against women: International perspectives and promising strategies (pp. 195-205). London: Routledge.

Jeffries, S. (2016). In the best interests of the abuser: Coercive control, child custody proceedings and the "expert" assessments that guide judicial determinations. Laws, 5(1), 1-17. 
Johnson, H., \& Hotton, T. (2003). Losing control: Homicide risk in estranged and intact intimate relationships. Homicide Studies, 7(1), 58-84.

Johnson, M.P. (2006). Conflict and control: Gender symmetry and asymmetry in domestic violence. Violence Against Women, 12(11), 1003-18.

Juodis, M., Starzomski, A., Porter, S., \& Woodworth, M. (2014). A comparison of domestic and non-domestic homicides: Further evidence for distinct dynamics and heterogeneity of domestic homicide perpetrators. Journal of Family Violence, 29(3), 299-313.

Kelly , L., \& Westmarland, N. (2016). Naming and defining 'domestic violence': Lessons from research with violent men. Feminist Review, 112, 113-127.

Kivivuori, J., \& Lehti, M. (2012). Social correlates of intimate partner homicide in Finland: Distinct or shared with other homicide types? Homicide Studies, 16(1), 60-77.

Loseke, D. (2003). Thinking about social problems (2nd ed.), New York: Walter de Gruyter Inc. Macdonald, G.S. (2016). Domestic violence and private Family Court proceedings: Promoting child welfare or promoting contact? Violence Against Women, 22(7), 832-852.

Messing, J. T., \& Thaller, J. (2014). Intimate partner violence risk assessment: A primer for social workers. British Journal of Social Work, 45(6), 1804-1820.

Myhill, A. (2015). Measuring coercive control: What can we learn from national population surveys? Violence Against Women, 21(3), 355-375.

National Institute on Drug Abuse (n.d.). DAST-10. Retrieved from https://www.drugabuse.gov/sites/default/files/files/DAST-10.pdf

NSW Domestic Violence Death Review Team (2015). Annual report 2013-2015. Sydney: NSW Government. 
Office of the Chief Coroner for Ontario (2015). Domestic Violence Death Review Committee 2013-2014 Annual report. Toronto: Office of the Chief Coroner.

Pence, E., \& Paymar, M. (1986). Power and control: Tactics of men who batter. Duluth, MN: Minnesota Program Development.

Randall, M. (2004). Domestic violence and the construction of 'ideal victims': Assaulted women's ‘image problems’ in law, St. Louis University Public Law Review, 23, 107-154.

Salovey, P., \& Rodin, J. (1988). Coping with envy and jealousy. Journal of Social and Clinical Psychology, 7(1), 15-33.

Sheehy, E. (2014). Defending battered women on trial: Lessons from the Transcripts. Vancouver: University of British Columbia Press.

Skinner, H.A. (1982). The drug abuse screening test. Addictive Behaviors, 7(4), 363-371.

Stark, E. (2007). Coercive control: How men entrap women in personal life. Oxford: Oxford University Press.

Stark, E. (2012). Looking beyond domestic violence: Policing coercive control. Journal of Police Crisis Negotiations, 12, 199-217.

Stockl, H., Devries, K., Rotstein, A., Abrahams, M., Campbell, J., Watts, C., \& Garcia Moreno, C. (2013). The global prevalence of intimate partner homicide: A systematic review. The Lancet, 382, 859-865.

Tanha, M., Beck, C.J.A., Figueredo, A.J. \& Raghavan, C. (2010) Sex differences in intimate partner violence and the use of coercive control as a motivational factor for intimate partner violence. Journal of Interpersonal Violence, 25, 1836-1854. 
Wilson, M., \& Daly, M. (1998). Lethal and non-lethal violence against wives and the evolutionary psychology of male sexual proprietariness. In R. E. Dobash \& R. P. Dobash (Eds.), Rethinking violence against women (pp. 199-230). Thousand Oaks, CA: Sage.

World Health Organization (2013). Global and regional estimates of violence against women: Prevalence and health effects of intimate partner violence and nonpartner sexual violence. Geneva: World Health Organization.

${ }^{i}$ Personality measures such as trait anger and self-control were included in the questionnaire but omitted from this analysis. 